\title{
Cerebral symptoms after whiplash injury of the neck: a prospective clinical and neuropsychological study of whiplash injury
}

Thierry M Ettlin, Udo Kischka, Sandra Reichmann, Ernst W Radii, Sabine Heim, Daniel à Wengen, D Frank Benson evaluations. Twenty one consecutive patients who sustained an acute whiplash injury and were seen in the Emergency Department, University Hospital, Basel, had a full neurological and comprehensive neuropsychological assessment, cervical $x$ rays, EEG, BAEP, MRI, and an otoneurological examination. Neuropsychological testing was repeated at three months postinjury in 15 patients and again at two years postinjury in 4 patients.

\section{Patients and methods \\ Selection}

Twenty six consecutive patients presented between November 1988 and June 1989, within one hour to one day following a typical whiplash injury. Five patients (two females and three males) dropped out of the study. Thus 21 patients were referred for the additional examinations described below. None had a history of previous cervical injury. There were 18 females, ranging in age from 18 to 46 years, and three males, from 24 to 35 years of age. The average patient age was $28 \cdot 8$ years, $28 \cdot 4$ years for the females and 29.3 years for the males. All had been involved in traffic accidents. The mechanism was a rear end impact in 15 patients, head-on collision in three patients and lateral impact in three patients. None experienced direct head trauma. All were actively employed before injury.

\section{Methods}

All patients had an immediate neurological check up and had a full neurological examination within three days. Each patient was asked for a description of the accident and the present complaints. They were then led through a structured interview with questions concerning their previous medical history and the exact time schedule the current symptoms had developed (see table 1 for the interview questions and results).

A full cervical radiographic series was performed shortly after admission to the Emergency Room.

EEG was performed within 3 to 8 days after the injury using a 16 channel system with 30 minutes of recording including photostimulation and EEG mapping.

BAEPs were recorded within 7 to 14 days with a click of $85 \mathrm{~dB}$ SL. The interpeak latencies I-III, III-V and I-V were measured out.

Otoneurological examination was performed within 14 days and included clinical testing of the vestibular system and a complete 
Table 1 Structured interview. Questions and results

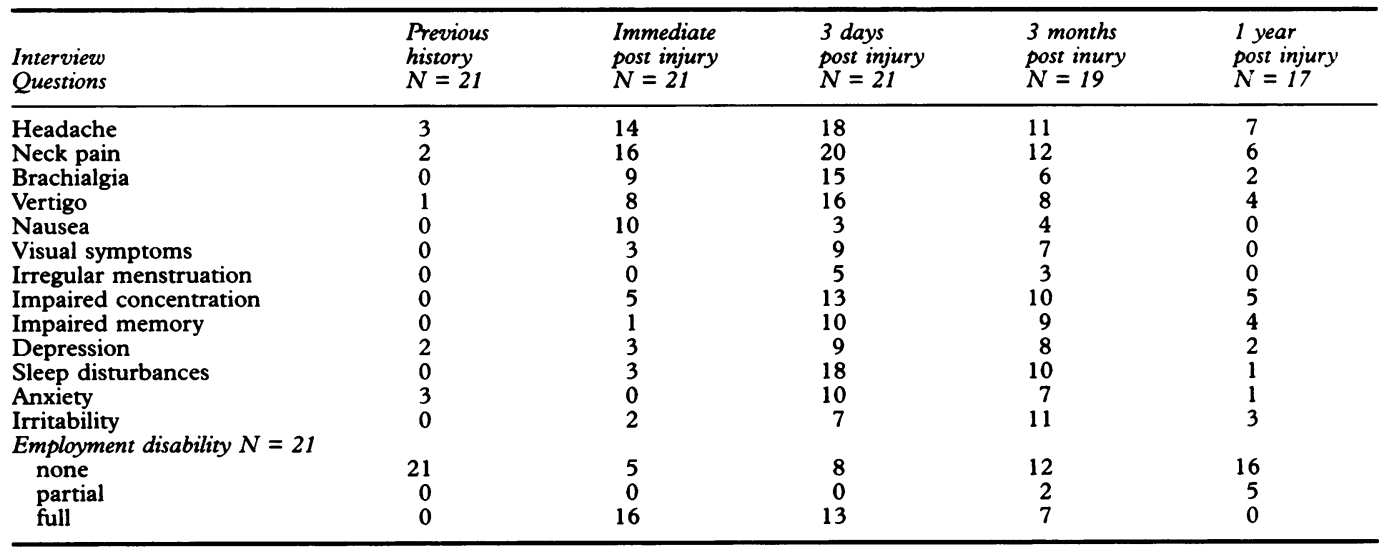

Figures indicate number of patients.

electronystagmography test battery (eye tracking test, optokinetic nystagmus test, rotating chair test, caloric test) and BAEPs. ${ }^{18}$ Peripheral vestibular deficit was suggested by either horizontal spontaneous nystagmus, canal paresis of more than $30 \%$ following caloric irrigation, or asymmetry in the rotating chair test. Central vestibular deficit was suggested by vertical, rotatory or dissociated spontaneous nystagmus, low gain or saccades in the eye tracking test, low gain in optokinetic nystagmus testing, deficient fixation suppression or pathological but symmetrical brain stem auditory responses. Nystagmus with decres-
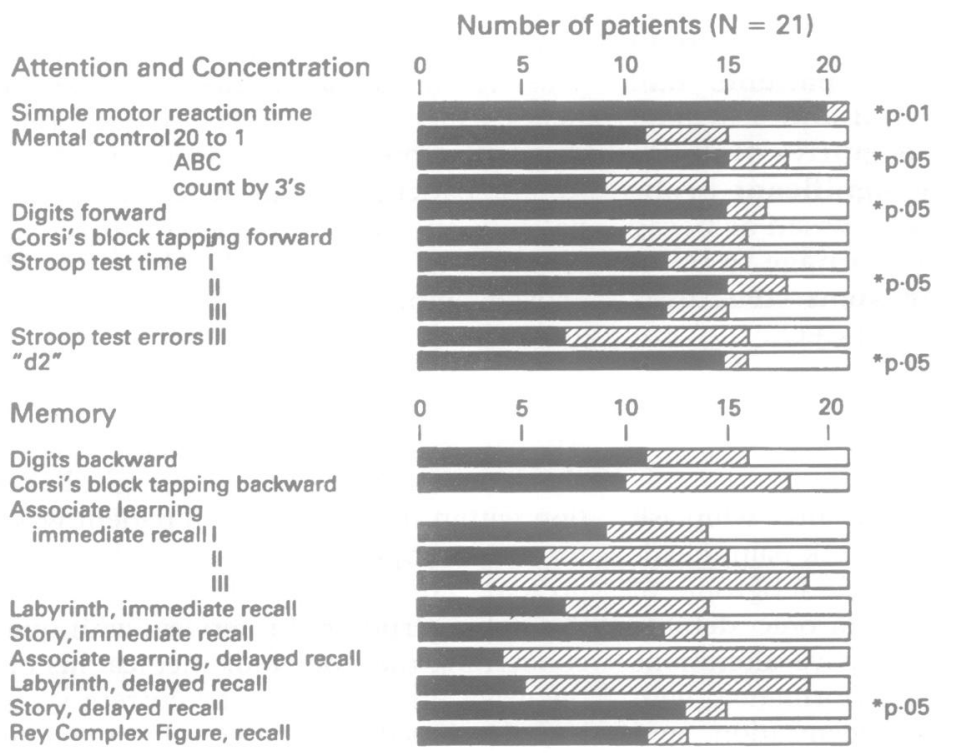

Higher cognitive functions
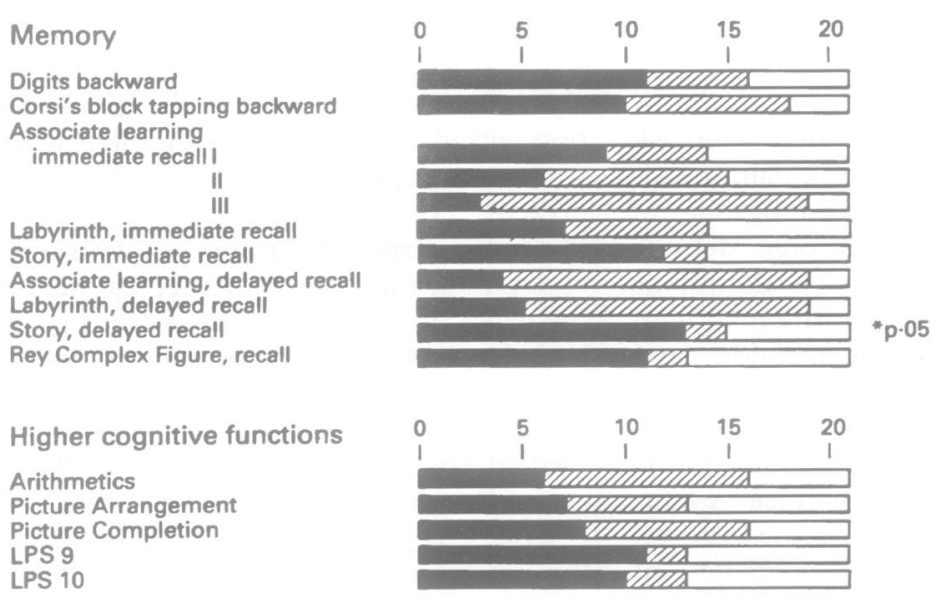

Patient performed poorer than control

Patient performed equal to control

Control performed poorer than patient

Figure Cases in which the patient performed poorer than the pair-matched control are drawn in black; the white bar indicates when the patient's performance was better and the hatched bar when patient and control performed equally. cendo in the cervical ocular reflex test was labelled as cervicogenic nystagmus. ${ }^{18}$

MRI of the brain was performed within 14 days on a Siemens System using a 1.5 Tesla magnetic field strength. Images were obtained in continuous $6 \mathrm{~mm}$ and $8 \mathrm{~mm}$-slices in the transaxial coronal planes using the spin-echo sequences $\mathrm{T} 1$ and $\mathrm{T} 2$. The entire brain including the brainstem was imaged.

Neuropsychological evaluation was performed within 3 to 7 days. Abridged versions of several formal tests ${ }^{19}$ were used to probe a broad range of neuropsychological functions. Attention was tested with simple motor reaction time, ${ }^{20}$ Wechsler's mental control and digits forward, ${ }^{21}$ Corsi's block tapping forward, ${ }^{22}$ Stroop Test II. ${ }^{23}$ Concentration was tested with Brickenkamp's “ $d 2$ ". ${ }^{24}$ Verbal and visual memory was tested with Wechsler's digits backward, associate learning and recall of a story; ${ }^{21}$ additional tests included Corsi's block tapping backward, ${ }^{22}$ Benton's labyrinth $^{25}$ and recall of the Rey-Osterreith complex figure. ${ }^{26}$ For higher cognitive functions we selected mental arithmetic, Wechsler's picture arrangement and picture completion, ${ }^{27}$ Stroop Test III $^{23}$ and two tests of visuospatial integration (LPS 9 and LPS 10) from the "Leistungspruefsystem". ${ }^{28}$ (Fig 1 and table 2 lists the tests used and the results).

For comparison of the neuropsychological test results each of the patients was matched with a healthy volunteer without any history of whiplash injury or other neurological dysfunction according to sex, age, education and professional level. The mean age of this control group was 27.8 years, 28.7 years for the females and 25.6 years for the males. The point score of each subject test was compared with the corresponding score of each pair-matched control test and the statistical significance of the score differences calculated using the Wilcoxon Statistic Test with Bonferroni-correction for multiple comparisons. The patients results of the additional examination (cervical $x$ ray, EEG, BAEP, otoneurological examination and MRI of the brain) were compared with reference data from the literature.

Follow up examinations included a neurological examination and interview at 3, 6, 12 and 24 months postinjury. Neuropsychological 
Table 2 Neuropsychological test results. Initial evaluation. Raw point scores. $N=21$

\begin{tabular}{|c|c|c|}
\hline & $\begin{array}{l}\text { Controls } \\
\text { mean }(S D)\end{array}$ & $\begin{array}{l}\text { Patients } \\
\text { mean }(S D)\end{array}$ \\
\hline 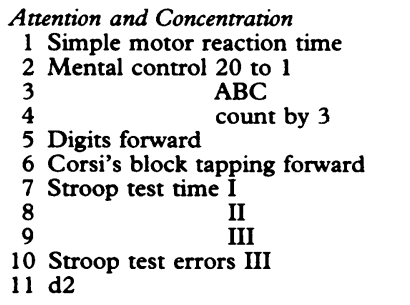 & $\begin{array}{c}0.19(0.02) \\
2.95(0.21) \\
2.57(0.81) \\
2.17(1.0) \\
7.85(0.91) \\
5.95(0.74) \\
11.62(1.59) \\
13.95(1.39) \\
22.0(6.07) \\
0.52(0.51) \\
457.2(71.6)\end{array}$ & $\begin{array}{c}0.27(0.1) \\
2.8(0.41) \\
2.3(0.86) \\
2.15(0.98) \\
6.42(1.26) \\
5.84(0.83) \\
13.2(3.25) \\
15.7(4.67) \\
25.6(7.39) \\
0.4(0.6) \\
389.2(72.0)\end{array}$ \\
\hline $\begin{array}{l}\text { Memory } \\
12 \text { Digits backward } \\
13 \text { Corsi's block tapping backward } \\
14 \text { Associate learning I } \\
15 \text { immediate recall II } \\
16 \text { III } \\
17 \text { Labyrinth immediate recall } \\
18 \text { Story immediate recall } \\
19 \text { Associate learning delayed recall } \\
20 \text { Labyrinth delayed recall } \\
21 \text { Story delayed recall } \\
22 \text { Rey complex figure delayed recall }\end{array}$ & $\begin{array}{c}6.71(1.3) \\
5.48(0.6) \\
8.09(1.09) \\
9.52(0.68) \\
9.95(0.22) \\
2.83(1.2) \\
12.91(2.4) \\
9.81(0.51) \\
1.19(0.51) \\
11.69(3.09) \\
12.31(2.81)\end{array}$ & $\begin{array}{c}5.33(1.19) \\
4.89(0.9) \\
7.95(1.57) \\
9.3(1.13) \\
9.84(0.5) \\
2.81(2.04) \\
11.26(3.4) \\
9.14(1.35) \\
1.32(0.95) \\
8.93(2.78) \\
11.18(1.9)\end{array}$ \\
\hline $\begin{array}{l}\text { Higher Cognitive Functions } \\
23 \text { Arithmetics } \\
24 \text { Picture arrangement } \\
25 \text { Picture completion } \\
26 \text { LPS 9 } \\
27 \text { LPS } 10\end{array}$ & $\begin{array}{c}14.86(1.35) \\
13.09(1.51) \\
9.91(0.3) \\
25.52(6.55) \\
32.33(5.49)\end{array}$ & $\begin{array}{c}15.0(1.58) \\
13.76(1.26) \\
9.48(0.6) \\
23.1(6.54) \\
25.2(7.48)\end{array}$ \\
\hline
\end{tabular}

The numbers in tests $5,6,11-16,18,19,21,22,24-27$ signify correct answers. The numbers in tests 10 and 17 denote errors. The numbers for tests $1,7,8,9$ stand for seconds. For tests $2-4$ a score was calculated from times and errors (a higher score means a better result).

assessment (a parallel version), was repeated at 3 months in 15 patients and at two years in 4 patients.

As both neuropsychological performance and response to electrophysiological testing may be vulnerable to centrally acting analgesics and muscle relaxants, medication during the period of testing was avoided when possible. Fourteen patients received no medication at all during the testing. The medication of the remaining seven is presented in detail below.

\section{Results}

Table 1 summarises the complaints and symptoms the patients reported in the structured interview on the pre-traumatic, immediate, three days, three months and one year postwhiplash injury and the frequency of employment disability. Though none of the patients apparently had direct head trauma, 12 could not give a precise description of the movement of their body and head at the moment of collision. Intensity and frequency of most of the reported symptoms were highest at 3 days post-injury. Immediately after the injury five patients were aware of decreased concentration. Within three days, 13 patients had noted concentration or memory problems. Sleep disturbance was reported by 18 patients within three days and 9 patients reported symptoms of depression including depressed mood, loss of energy and decreased motivation; only 2 of the 9 had a previous history of depression. Interestingly, 7 of the 18 female patients reported menstrual irregularities; one had irregular menstrual bleeding the day following the injury and 4 more within three days; one reported an interruption of menstrual bleeding and one a delay in the menstrual cycle.

On neurological examination all patients showed tenderness over the cervical region with some limitation of motion of the cervical spine. Sensory loss was present and included more than one dermatomal segment of the upper extremities in most patients, but arm weakness was more diffuse than radicular. In three patients the deep tendon reflexes were decreased on the painful arm. All other results on routine neurological examination were negative.

Cervical spine $x$ rays were obtained in 19 of the 21 patients. Thirteen showed a loss of cervical lordosis; two a sharp reversal of lordosis at C4-5 or C5-6.

EEGs were obtained in 18 patients and were focally slow in 8 . Occipital focus was present in 4 , temporo-occipital in 2, parieto-occipital in one, and temporoparietal in one. One patient had mild overall slowing and one showed paroxysmal bifrontal theta waves. Eight had normal EEGs.

BAEPs were obtained in 14 patients. No abnormalities were noted.

Otoneurological examinations were obtained in 18 patients. Ten had abnormalities: three showed findings consistent with central vestibular dysfunction, one had findings consistent with a peripheral vestibular dysfunction, four showed a cervicogenic nystagmus. In one there was a combination of central vestibular dysfunction and a cervicogenic nystagmus and one had peripheral vestibular dysfunction plus cervicogenic nystagmus.

MRI obtained in 15 patients were without abnormalities except for one small, nonspecific white matter lesion in a 36 year old female.

Table 2 shows the raw point scores of each neuropsychological subtest for the patient and control group. Figure 1 shows the performances of each patient compared with the performance of the corresponding pair- 
matched control subject for each test. In the subtests related to attention and concentration the score differences were statistically significant. From 21 patients, 20 showed a higher simple motor reaction time $(p=0.01)$ and 15 performed poorer in Wechsler's mental control subtest "ABC" $(p=0.05)$, digit span ( $p=$ $0 \cdot 05)$, sustained attention test Stroop II $(\mathrm{p}=$ $0.05)$ and concentration test " $d 2 "(p=0.05)$. Although 10 patients complained about impaired memory, the only significant difference demonstrated in formal memory tests was the poorer performance of the patients in the delayed recall of a story $(p=0.05)$. As the learning ability of both verbal and visuospatial material was similar in both patients and controls, the decreased ability to recall suggests a retrieval dysfunction. No differences were shown on subtests probing higher cognitive functions.

Seven patients were on medication during the period of different testings. They were taking either a combination drug of the muscle relaxant orphenadrine citrate and the analgesic paracetamol, dihydroergotamine mesylate or the non-steroidal antiinflammatory agents ibuprofen or diclofenac sodium. All four patients taking medication at the time of EEG recording showed focal slowing. From the three patients taking medication during otoneurological examination one showed a combination of central vestibular dysfunction and cervicogenic nystagmus, one cervicogenic nystagmus and one normal results. From four patients on medication during neuropsychological testing three showed lower results than their controls in the subtests related to attention and concentration. The fourth patient, taking ibuprofen, did not show a lower performance.

Nineteen patients returned for follow up neurological examination and interview three months and 17 one and two years after the injury. Structured interviews (table 1) suggested that although cerebral symptoms, poor concentration and subjective memory dysfunction, depression, anxiety and irritability had improved in most, only 5 patients reported complete recovery three months after the injury. In addition, four reported late onset symptoms including depression, anxiety, irritability and sleep disturbances.

Follow up examination two years postinjury showed that the course of symptoms had been stable since one year after the injury in all patients. Thus from 17 patients re-examined one year after the injury 10 reported complete recovery. Seven patients had chronic or intermittent headache, 6 together with neck pain, 4 together with vertigo and 2 together with depression. Additionally, five of these patients had still poor concentration and subjective memory dysfunction. One other had isolated word finding problems and memory dysfunction.

Follow up neuropsychological assessment (a parallel version) could be obtained from 15 patients at three months postinjury and a second follow up testing from four patients with persistent employment disability one or two years postinjury. The test results showed that of the 14 retested patients with initial attentional deficits, two now had results equal to their controls, 10 others had improved but two actually had lower test results than before. Of 13 retested patients with initial deficits in concentration, 8 were improved, 4 unchanged and one had poorer results.

Three patients were on medication at the time of retesting. Two were taking diclofenac sodium and ibuprofen, one showing poorer, one improved and one unchanged scores compared to the initial evaluation.

At three months, 12 patients had returned to full employment; three had been off work for two days only and five had no employment disability at all (table 1).

Nine had not returned to regular employment after three months; seven were still disabled and 2 had returned to partial employment. The reason was chronic or intermittent headache or/and neck pain or/and vertigo plus cognitive dysfunction. Five of these patients were adamant that cognitive disturbances interfered with their performance at work independently from intermittent or insignifiicant head and neck pain. At one and two year post injury 16 patients had returned to full employment. Five patients were still partially disabled: Four of these belonged to the 5 patients with persisting cognitive dysfunction; the fifth had isolated headache and neck pain. Repeated neuropsychological testing at one year in two and two year postinjury in the other two patients with chronic cognitive dysfunction demonstrated that the test results were unchanged compared to previous testings.

\section{Discussion}

The patient population in this prospective study of whiplash injury patients is different from most published studies that are attained retrospectively with selected patients suffering a chronic course. Only two studies of whiplash patients in the acute stage are known: one report focussed on EEG findings only; ${ }^{29}$ the other, a recent follow up study on 78 patients, demonstrated that initial neck pain intensity, cognitive impairment as indicated on a selfrating questionnaire and age predicted the outcome afterwhiplash injury but psychosocial factors, negative affect and personality traits did not. ${ }^{17}$

In our group dysfunction of attention and concentration was more frequent than expected. When compared with pair-matched controls the patients showed a significant increase in simple motor reaction time and significantly decreased sustained attention, digit span and concentration. In addition, the frequency for emotional problems was high; 9 patients reported depression early in the course; 7 of these individuals had never previously experienced significant depressive reactions.

On cervical spine $x$ ray loss of cervical lordosis and sharp reversal of cervical lordosis at C4-5 or C5-6 found in our patients can both also occur in asymptomatic poeple and have poor prognostic value. ${ }^{30}$

The EEG was abnormal in 10 of 18 acute 
subjects. Several EEG studies have reported abnormalities in $30-50 \%$ of whiplash patients $^{7131-33}$ but a recent study ${ }^{29}$ reported minimal abnormalities in only three of 68 patients. Considering that mild overall slowing is found in $10-15 \%$ of normal subjects, ${ }^{34}$ the significance of mild overall slowing with focal emphasis in our 10 patients remains unclear.

The normal results with MRI and BAEP studies confirm the negative results of Yarnell et $a^{12}$ who studied chronic whiplash patients and show that MRI and BEAP were also normal when obtained in the acute stage.

The otoneurological examination is reported as a sensitive method for detecting vestibular dysfunction following whiplash trauma. ${ }^{35-37}$ Our results (10 abnormal out of 18 tested) demonstrate that the number with vestibular dysfunctions early in the course is high.

At one year postinjury 10 patients reported complete recovery and 16 were back to full employment. In one patient, however, word finding problems and memory dysfunction persisted and 4 patients remained partially disabled mainly because of cognitive dysfunction.

The aetiology of cerebral symptoms following whiplash injury has been controversial. Brain lesions have been produced in experimental animals, ${ }^{38-40}$ and cases of proven cerebral contusion and subdural haematoma have been reported following whiplash injuries, ${ }^{41}$ but many studies ${ }^{591542}$ have interpreted cerebral symptoms as indication of a neurotic personality.

What causes, other than brain damage, could explain the early findings?

Medication such as analgesics and muscle relaxants often prescribed to treat the pain of whiplash injury are known to influence neuropsychological and electrophysiological data. At most, medication played only a minor role in our patients as 14 had no medication at all during the period of testing and those using medication had no more positive findings in any of the tests than those without medication.

Pain and distress can also cause inattention and decreased concentration. In fact, these conditions are difficult to measure independently and pain was probably a factor for cognitive dysfunctioning in some of the patients. Other patients, particularly the four with persistent employment disability, showed chronic attention and concentration problems independent of pain intensity and one patient reported word finding problems as the only symptom.

Depression could impair attention and concentration and as 9 patients had symptoms of depression the differentiation from other causes remains difficult. Only two of the patients had previous episodes of depression; most were psychiatrically healthy subjects and their post injury depression deserves consideration as an organic depression.

Finally, secondary gain is often thought to contribute to post whiplash symptoms but can most probably be excluded in our patients. The neuropsychological impairments were limited to psychomotor functions and it would be expected that psychogenic causation would produce inhomogeneous test results and also affect higher cognitive functions.

The "post-concussion syndrome" lists similar cognitive, emotional and somatic symptoms and has been plagued by the same organic/psychogenic controversy. The neuropsychological dysfunctions seen in our patients with whiplash injury correspond to problems noted in the early stage of recovery from concussion. ${ }^{434}$

Attention and concentration deficits, emotional changes, sleep disturbances and menstrual irregularities suggest possible damage to basal frontal and upper brain stem structures, sites of limbic and hypothalamic connections. The reticular formation and its projections also occupy this area and are known to play a major role in the regulation of attention and concentration. ${ }^{4546}$ Electrophysiological studies ${ }^{353738}$ also suggest that the functional abnormalities following whiplash injury evolve from disturbances in the midbrain, reticular formation, vestibular nuclei and the hypothalamus as well as the basal orbital and septal frontal regions. These areas are particularly prone to traumatic brain injury. ${ }^{47}$

Although a wide range of other aetiologies could be responsible for the cerebral symptoms our findings may be due to organic brain dysfunction after whiplash injury.

1 Zenner P. Die Schleuderverletzun der HWS und ihre Begutachtung. Berlin: Springer Verlag 1987.

2 Hirsch SA, Hirsch PJ, Hiramoto $H$, Weiss A. Whiplash syndrome. Orthop Clin of North Am 1988;19:791-5.

3 Gay JR, Abbott KH. Common whiplash injuries of the neck. f $A M A$ 1953;152:1698-704.

4 Janes JM, Hooshmand $H$. Severe extension, flexion injuries of the cervical spine. Mayo Chir Proc 1965;40:353-9.

5 Hodge JR. The whiplash neurosis. Psychosomatics 1971; 12:245-9.

6 Erdmann H. Die Schleuderverletzung der Halswirbelsaeule. Die Wirbelsaeule in Forschung und Praxis. Stuttgart: Hippokrates Verlag 1973.

7 Wiesner H, Mumenthaler M. Schleuderverletzung der Halswirbelsaeule. Ther Umsch 1974;31:640-9.

8 Berstad JR, Bacrum B, Loecher EA, Mogstad RE, Spastad O. Whiplash: Chronic organic brain syndrome withou hydrocephalus ex vacuo. Acta Neurol Scand 1975;51 268-84.

9 Kraemer G. HWS-Schleudertraumen. Zur Pathogenese de zerebralen Beteiligung und persistierenden Stoerungen. Med Welt 1983;34:1134-40.

10 Berry H. Psychological aspects of whiplash injury. In Wilkins RH, Rengachary SS, eds. Neurosurgery. NewYork: McGraw-Hall, 1985.

11 Foletti GB, Regli F. Le traumatisme cervical indirect: facteurs de mauvais prognostic a long terme. Schweiz Rundsch Med Prax 1987;76:1304-9.

12 Yarnell PR, Rossie GV. Minor whiplash head injury with major debilitation. Brain Inj 1988;2:255-8.

13 Laubichler W. Zur Aetiologie des neurastheniformen "Psychosyndroms" nach Verletzungen der Halswirbelsaeule, chosyndroms" nach Verletzungen der Halswirbelsaeule, Beitr Gerichtl Med 1988;46:439-49.

14 Radanov BP, Dvorak J, Valach L. Psychische Veraenderungen nach Schleuderverletzungen der Halswirbelsaeule. Schweiz Med Wochenschr 1989;119:536-43.

15 Ettlin TM, Kischka U, Kaeser HE. Kognitive und psychische Stoerungen nach HWS-Schleudertrauma Schweiz Rundsch Med Prax 1989;78(36):967-9.

16 Kischka U, Ettlin TM, Heim S, Schmid G. Cerebra symptoms following whiplash injury. Eur Neurol 1991; 31:136-40.

17 Radanov BP, Di Stefano G, Schnidrig A, Ballinari P. Role of psychosocial stress in recovery from common whiplash. Lancet 1991;338:712-15.

18 Allum JHR, Ura M, Honegger F, Pfaltz CR. Classification of peripheral and central (pontine infarction) vestibular of periph: Selection of a neurootological test battery usin discriminant ansis. Acta Otolaryngol (Stockh) 1991; 111:16-26. 
19 Perret E. Gehirn und Verhalten. Bern: Verlag Hans Huber, 1973.

20 Brickenkamp R. Handbuch apparativer Verfahren in der Psychologie. Goettingen: Hogrefe, 1986.

21 Wechsler D. A standardized memory scale for clinical use. $\boldsymbol{f}$ Psychol 1945;19:87-95.

22 Milner B. Interhemispheric differences in the localization of psychological processes in man. Brit Med Bull 1971;27: psychol.
$272-7$.

23 Stroop JR. Studies of interference in serial verbal reactions. f Exp Psychol 1935;18:643-62

24 Brickenkamp R. Test d2-Aufmerksamkeits-Belastungstest. Goettingen: Hogrefe, 1962.

25 Benton AL, Hamsher K.de S. Multilingual aphasia examination. Iowa City: University of Iowa 1976. (Manual, rev, 1978).

26 Rey A. L'examen psychologique dans les cas d'encephalopathie traumatique. Arch de Psychol 1941;28(112): 286-340.

27 Wechsler C. Wechsler Adult Intelligence Scale-Revised. New York: Psychological Corporation, 1981.

28 Horn W. Leistungspruefsystem (L-P-S). Goettingen: Hogrefe, 1983.

29 Jacome DE. EEG in whiplash: a reappraisal. Clin Electroencephalogr 1987;18:41-5.

30 Gore DR, Sepic SB, Gardner GM. Roentgenographic findings of the cervical spine in asymptomatic people. Spine 1986;11:521-4.

31 Fischer D, Palleske H. Das EEG nach der sogenannten Schleuderverletzung der Halswirbelsaeule. Zentralbl Neurochir 1976;37:25-35.

32 Pavlincova E, Mumenthaler M, Karbowski K. Elektroenzephalographische Befunde bei reinen Schleuderverletzungen der Halswirbelsaeule. Nervenarzt 1977;48:505-8.

33 Torres F, Shapiro SR. Electroencephalograms in whiplash injury. Arch Neurol 1961;5:28-35.
34 Christian W. Klinische Elektroencephalographie. Stuttgart: Georg Thieme Verlag, 1975:43.

35 Hinoki $M$. Vertigo due to whiplash injury: a neurootological approach. Acta Otolarymgol 1984;Supp419:9-29.

36 Toglia JU. Actate flexion-extension injury of the neck. Electronystagmographic study of 309 patients. Neurology 1976;26:808-14

37 Ushio N, Ishida I, Koike $S$ et al. Studies on inverted optokinetic nystagmus in cases with whiplash injury. Pract Otol (Kyoto) 1971;64:493-509.

38 Kawakami $M$. EEG findings in experimental whiplash injury. In: Hami K, ed. Whiplash injury. Tokyo: KanokaraShuppan, 1972:136-49.

39 Miura Y, Tanaka $M$. Disturbances of the venous system in the head and neck regions in rabbits with whiplash injury. Brain Nerve (Tokyo) 1970;2:217-23.

40 Ommaya AK, Faas F, Yarnell P. Whiplash injury and brain damage. $\Im A M A$ 1968;204:285-9.

41 Ommaya AK, Yarnell P. Subdural hematoma after whiplash injury. Lancet 1969;11:237-9.

42 Buehring $M$. Reflex dystrophy following so-called whiplash injury of the cervical spine. $Z$ Orthop 1984;122:281-6.

43 Gronwall D, Wrightson P. Delayed recovery of intellectual function after minor head injury. Lancet 1974;2:605-9.

44 Dikmen S, Reitan RM. Emotional sequelae of head injury. Ann Neurol 1977;2:492-4.

45 Heilman KM, Watson RT, Valenstein E. Neglect and related disorders. In: Heilman KM, Valenstein E, eds. Clinical neuropsychology. New York: Oxford University Press 1985:252-84.

46 Mesulam MM. Attention, confusional states and neglect. In: Mesulam MM, ed. Principles of behavioral neurology. Philadelphia: FA Davis, 1985:135-40.

47 Alexander MP. Traumatic brain injury. In: Benson DF, Blumer D, eds. Psychiatric aspects of neurologic disease Vol 2. New York: Grune and Stratton, 1982:219-48. 